\title{
$\mathrm{TiO}_{2}-\mathrm{CaO}-\mathrm{Al}_{2} \mathrm{O}_{3}-\mathrm{Na}_{2} \mathrm{O}-\mathrm{SiO}_{2} \mathrm{Cam}$ Yapısının Elektriksel ve Optik Özellikleri Üzerine ZnO Miktarının Etkisi
}

\author{
Sadiye Çetinkaya Çolak, İdris Akyüz, Ferhunde Atay \\ Eskişehir Osmangazi Üniversitesi Fen-Edebiyat Fakültesi Fizik Bölümü, 26480 Eskişehir, Türkiye \\ sccolak@ogu.edu.tr
}

\begin{tabular}{cl} 
& Özet \\
\cline { 2 - 3 } & Bu çalışmada, klasik erime-söndürme tekniği ile $1 \mathrm{TiO}_{2}-3 \mathrm{CaO}-1 \mathrm{Al}_{2} \mathrm{O}_{3}-25 \mathrm{Na}_{2} \mathrm{O}-(70-\mathrm{x}) \mathrm{SiO}_{2}: x \mathrm{ZnO}(\mathrm{x}=0,5$, \\
Anahtar elimeler & $10,15 \%$ ağılık) yapısında dört adet cam yapısı hazırlanmıştır. Üretilen bu camların elektriksel ve optik \\
Çinko oksit; & özelliklerinin incelenmesi amaçlanmıştır. Iletim mekanizmalarını araştırmak için sıcaklığa bağlı \\
Silikat cam; & elektriksel ölçümleri alınmış ve klasik Arrhenius bağıntısı ile aktivasyon enerjileri saptanmıştır. Üretilen \\
Optik özellikler; & cam yapıların soğurma spektrumları kullanılarak optik bant aralıkları hesaplanmıştır. Ayrıca, \\
Elektriksel özellikler. & spektroskopik elipsometri tekniği kullanılarak numunelerin kırılma indisi ve sönüm katsayısı değerleri \\
& belirlenmiştir. Alınan ölçümler sonucunda, cam yapısına eklenen ZnO miktarı arttıkça aktivasyon \\
& enerjilerinin genelde arttığı, kırılma indisi değerlerinin azaldığı ve geçirgenlik değerlerinin arttığı \\
& gözlenmiştir. Özellikle \%15 ZnO içeren silikat cam yapısının görünür bölgedeki geçirgenliği \%95'e \\
& ulaşmıştır.
\end{tabular}

\section{The Effect of ZnO Doping Amount on the Electrical and Optical Properties of $\mathrm{TiO}_{2}-\mathrm{CaO}-\mathrm{Al}_{2} \mathrm{O}_{3}-\mathrm{Na}_{2} \mathrm{O}-\mathrm{SiO}_{2}$ Glass Structure}

\begin{tabular}{|c|c|}
\hline & act \\
\hline $\begin{array}{c}\text { Keywords } \\
\text { Zinc oxide; } \\
\text { Silicate glass; } \\
\text { Optical properties; } \\
\text { Electrical properties. }\end{array}$ & $\begin{array}{l}\text { In this study, four glass structures of the composition } 1 \mathrm{TiO}_{2}-3 \mathrm{CaO}-1 \mathrm{Al}_{2} \mathrm{O}_{3}-25 \mathrm{Na}_{2} \mathrm{O}-(70-\mathrm{x}) \mathrm{SiO}_{2}: \mathrm{xZnO}(\mathrm{x}= \\
0,5,10,15 \text {, weight \%) were prepared by the melting quenching technique. It is aimed to investigate the } \\
\text { electrical and optical properties of these glasses. Temperature dependent electrical measurements } \\
\text { were carried out to analyzed the conduction mechanisms and activation energies determined by } \\
\text { classical Arrhenius relation. Optical band gap values were calculated using absorption spectrums of } \\
\text { prepared glass structures. Also, refractive index and extinction coefficient values of samples were } \\
\text { determined by using Spectroscopic Ellipsometry (SE) technique. As a result of measurements, it is } \\
\text { observed that the activation energy generally increases, the refractive index decreases, and the } \\
\text { transmittance value increases by the increase of the } \mathrm{ZnO} \text { amount. Especially, the transmittance of the } \\
\text { silicate glass structure with } 15 \% \mathrm{ZnO} \text { content has been reached to } 95 \% \text { in the visible region. }\end{array}$ \\
\hline
\end{tabular}

(c) Afyon Kocatepe Üniversitesi

\section{Giriş}

Cam, hemen hemen her teknolojik uygulamada yaygın olarak kullanılan bir malzemedir. Çok farklı kimyasal sistemlerle cam oluşturmak mümkünse de, ekonomik olarak en önemli grup, oksit camlardır. Bunlardan en önemlileri, $\mathrm{SiO}_{2}$, $\mathrm{B}_{2} \mathrm{O}_{3}, \mathrm{P}_{2} \mathrm{O}_{5}$ ve $\mathrm{GeO}_{2}$ 'dir. $\mathrm{Bu}$ oksitler tek başlarına cam oluşturabildikleri gibi, bileşime başka oksitlerin ilavesi ile de çok çeşitli ve ekonomik değeri olan camlar elde edilebilir
(Kocabağ, 2002). Oksit camlar içerisinde silika camlar, kimyasal dayanımları, yüksek elektriksel dirençleri, düşük genleşme katsayıları, yüksek ışık geçirgenlikleri gibi özellikleriyle öne çıkmaktadırlar (Chimalawong et al. 2016).

Görünür bölgede yüksek ışık geçirgenliğine sahip olmasıyla dikkat çeken ZnO, önemli bir yariletken malzemedir. Oda sıcaklığında 3,3 eV'luk geniş bant aralığına sahip olmasından dolayı güneş hücreleri ve optoelektronik 
uygulamalarda sıklıkla kullanılır (Ding et al. 2008). Son yıllarda ZnO içeren camlar, çeşitli teknolojik alanlardaki kullanımlarından dolayı dikkat çekmektedir (Morsi et al. 2016). Özellikle, yüksek oranda ZnO içeren silikat camlar şeffaf dielektrik katmanlar ve plazma ekran panallerindeki teknik uygulamaları ile öne çıkmaktadır (Busio and Steigelmann 2000). ZnO, cam kompozisyonuna bağlı olarak, ağ yapıcı ve ağ düzenleyici olarak rol alabilmektedir (Rosenthal ve Garofalini 1987). Silikat cam içerisinde çinko oksidin ikili rolü üzerine yapılan çalışmalar oldukça kısıtlıdır.

Bu çalışmada, ekonomik bir yöntem olan erimesöndürme tekniği ile farklı oranlarda $\mathrm{ZnO}$ içeren silikat cam yapıları üretilerek, bu camların sıcaklığa bağlı elektriksel iletkenlik ve optik özellikleri incelenmiş ve ZnO'nun cam yapısında üstlendiği rol tartışıımıştır.

\section{Materyal ve Metot}

$1 \mathrm{TiO}_{2}-3 \mathrm{CaO}-1 \mathrm{Al}_{2} \mathrm{O}_{3}-25 \mathrm{Na}_{2} \mathrm{O}-(70-\mathrm{x}) \mathrm{SiO}_{2}: \quad \mathrm{xZnO}$ $(x=0,5,10,15 \%$ ağırlık) yapısındaki dört farklı cam, klasik erime-söndürme tekniği kullanılarak üretilmiştir. Hazırlanan cam yapıların detaylı kompozisyonları Tablo 2.1.'de verilmektedir. Camı oluşturacak oksitler gerekli miktarda hassas terazide tartılarak, temiz bir kap içerisinde karıştırılmış ve platin kroze içerisine konmuştur. Kroze içerisindeki kimyasallar, 1500 ${ }^{\circ} \mathrm{C}$ sıcaklığa ayarlanmış yüksek sıcaklık fırınında 3 saat tutularak eritilmiştir. Bu süre sonunda eriyik haline gelmiş cam, silindirik şeklindeki kalıba dökülerek şekillendirilmiş ve derhal daha önceden $450^{\circ} \mathrm{C}^{\prime}$ ye ayarlanmış tavlama fırınına konmuştur. Tavlama fırınında yaklaşık 1 saat bekletilen cam numuneler daha sonra oda sıcaklığına dek soğutulmaya bırakılmıştır. Elde edilen cam bloklar ölçümlere hazırlanması için kesme ve parlatma işlemlerinden geçirilmiştir. Üretilen camların elektriksel özdirenç değerlerinin sıcaklığa bağımlıı̆ını incelemek ve iletim mekanizmalarını araştırmak amacıyla 65$420 \mathrm{~K}$ sıcaklık aralığında direnç ölçümleri, HotStage yüksek sıcaklık elektriksel ölçüm cihazı ile desteklenen, kryostat sistemi kullanılarak alınmıştır.

Tablo 2.1. ZnO içeren silikat cam yapıların kodları ve kompozisyonları.

\begin{tabular}{|c|c|}
\hline Cam Kodu & Cam Kompozisyonu \\
\hline SZO & $\% 1 \mathrm{TiO}_{2}-\% 3 \mathrm{CaO}-\% 1 \mathrm{Al}_{2} \mathrm{O}_{3}-\% 25 \mathrm{Na}_{2} \mathrm{O}-\% 70 \mathrm{SiO}_{2}$ \\
\hline SZ5 & $\begin{array}{c}\% 1 \mathrm{TiO}_{2}-\% 3 \mathrm{CaO}-\% 1 \mathrm{Al}_{2} \mathrm{O}_{3}-\% 25 \mathrm{Na}_{2} \mathrm{O}-\% 5 \mathrm{ZnO}- \\
\% 65 \mathrm{SiO}_{2}\end{array}$ \\
\hline SZ10 & $\begin{array}{c}\% 1 \mathrm{TiO}_{2}-\% 3 \mathrm{CaO}-\% 1 \mathrm{Al}_{2} \mathrm{O}_{3}-\% 25 \mathrm{Na}_{2} \mathrm{O}-\% 10 \mathrm{ZnO}- \\
\% 60 \mathrm{SiO}_{2}\end{array}$ \\
\hline SZ15 & $\begin{array}{c}\% 1 \mathrm{TiO}_{2}-\% 3 \mathrm{CaO}-\% 1 \mathrm{Al}_{2} \mathrm{O}_{3}-\% 25 \mathrm{Na}_{2} \mathrm{O}-\% 15 \mathrm{ZnO}- \\
\% 55 \mathrm{SiO}_{2}\end{array}$ \\
\hline
\end{tabular}

Tüm numunelerin ölçülen direnç değerlerinden yararlanılarak, her bir sıcaklık değeri için elektriksel özdirenç ve iletkenlik değerleri hesaplanmıştır. In $(\sigma) \sim 1000 / T$ ve $\ln (\sigma \mathrm{T}) \sim 1000 / T$ değişim grafikleri çizilerek farklı sıcaklık bölgelerinde aktivasyon enerji değerleri belirlenmiştir.

Numunelerin geçirgenlik ve soğurma spektrumları Shimadzu UV-VIS 2550 Spektrofotometre cihazı ile ve Tauc eğrileri yardımıyla optik bant aralığı değerleri belirlenmiştir. OPTO $\$ 9000$ Spektroskopik Elipsometre cihazı ile tüm cam numunelerin kırılma indisi ve sönüm katsayısı gibi optik sabitleri belirlenmiştir.

\section{Bulgular}

\subsection{Elektriksel Özellikler}

Elektriksel ölçümler 65-420 K sıcaklık aralığında, sandviç formda kontaklar kullanılarak gerçekleştirilmiştir. Analizler sonucunda tüm cam yapıları için öncelikle oda sıcaklığındaki elektriksel özdirenç değerleri hesaplanmıştır. Daha sonra sıcaklığa bağlı elektriksel iletkenlik değerleri incelenerek cam yapıların iletim mekanizmaları hakkında yorumlar yapılmıştır. 


\subsection{1. Üretilen cam yapıların elektriksel özdirenç değerleri}

Tablo 3.1'de \%1 $\mathrm{TiO}_{2}-\% 3 \mathrm{CaO}-\% 1 \mathrm{Al}_{2} \mathrm{O}_{3}-\% 25$ $\mathrm{Na}_{2} \mathrm{O}-\%(70-x) \mathrm{SiO}_{2}: x \mathrm{ZnO} \quad(x=0,5,10,15)$ cam yapıları için oda sıcaklığında hesaplanan elektriksel özdirenç değerleri verilmiştir.

Tablo 3.1. Silikat cam yapıların oda sıcaklığındaki özdirenç değerleri.

\begin{tabular}{lc}
\hline Cam kodu & Özdirenç $(\Omega \mathrm{cm})$ \\
\hline SZ0 & $5.1 \times 10^{9}$ \\
\hline SZ5 & $3.6 \times 10^{9}$ \\
\hline SZ10 & $5.0 \times 10^{9}$ \\
\hline SZ15 & $5.9 \times 10^{9}$ \\
\hline
\end{tabular}

Tablo 3.1. incelendiğinde ZnO ilavesiyle SZ cam yapılarının elektriksel özdirenç değerlerinde önemli bir değişimin olmadığı ve değerlerin aynı mertebede kaldığı görülmektedir.

\subsection{2. Üretilen cam yapıların sıcaklığa bağlı elektriksel özelliklerinin incelenmesi}

Amorf katılarda dc iletim mekanizmaları temel olarak üç grupta incelenebilir.

1. Isıl aktivasyon süreci: Bu süreçte oda sıcaklığının üzerinde alınan veriler lineer bir değişim olarak karşımıza çıkar. Bu durum aşağıda verilen Arrhenius bağıntısıyla tanımlanabilir.

$\sigma(T)=\sigma_{o} \exp [-\Delta E / k T]$

(1)

burada $\sigma_{o}$ ilk exponansiyel değer, $\Delta \mathrm{E}$ aktivasyon enerjisi, $\mathrm{k}$ Boltzmann sabiti, $\mathrm{T}$ ise mutlak sıcaklıktır.

2.Küçük polaran sıçrama (SPH) mekanizması: $\mathrm{Bu}$ mekanizmada oda sıcaklığının altında alınan veriler lineer bir değişim olarak kendini gösterir. Bu durum aşağıda verilen bağıntı ile tanımlanabilir.

$$
\sigma(T)=\left(\sigma_{\circ} / T\right) \exp [-\Delta E / k T]
$$

\section{Değişken mesafeli sıçrama (VRH)} mekanizması: Değişken mesafeli sıçrama modelinde iletkenlik sıcaklıkla $T^{(-1 / 4)}$ şeklinde bir değişim sergiler ve

$$
\sigma(T)=\sigma_{o} \exp \left[-\left(T_{0} / T\right)^{1 / 4}\right]
$$

$$
\begin{aligned}
& \text { denklemiyle ifade edilir. Burada } T_{\circ} \\
& \text { karakteristik sıcaklıktır. Bu denklem, oda } \\
& \text { sıcaklığından düşük sıcaklıklarda iletkenlik } \\
& \text { eğrisi lineer olmayan davranış gösterirse } \\
& \text { uygulanabilir (Abdel-Wahab et al. 2006). }
\end{aligned}
$$

Üretilen tüm cam yapıları için In $(\sigma) \sim 1000 / T$ grafiklerinde iletkenliğin farklı davranışlar sergilediği bölgeler tespit edilmiştir. Yüksek sıcaklıklarda bu grafiklerde lineerliğin görüldüğü bölge I. Bölge olarak adlandırılmıştır. Bu bölgeden sonra lineerlikten sapmanın görüldüğü bölge II. Bölge olarak adlandırılmıştır. Tüm cam yapıları için kullanılan bu sınıflandırma şematik olarak şekil 3.1'de verilmektedir. Her bir cam yapısı için I. Bölgede Eşitlik (1) kullanılarak aktivasyon enerjileri $\left(E_{a}\right)$ hesaplanmıştır. Bu bölgede iletkenlikte klasik Arrhenius davranışının etkin olduğu düşünülerek analizler yapılmıştır. Sıçrama mekanizmasının devreye girdiği II. Bölge için, daha yukarıda bahsedilen $\mathrm{SPH}$ ve VRH iletim mekanizmaları değerlendirilmiş ve bu bölgelerde sıcaklığa bağlı iletkenlik grafikleri çizildiğinde SPH mekanizması için daha iyi bir uyum yakalandığı görülmüştür. Bu nedenle II. Bölgedeki elektriksel iletkenlik verileri SPH mekanizmasına göre açıklanmıştır. Bu bölge için, Şekil 3.2'de şematik olarak gösterilen In $(\sigma T) \sim 1000 / T$ grafikleri çizilerek, küçük polaran sıçrama (SPH) mekanizması için aktivasyon enerjileri $\left(E_{s 1}\right.$ ve $\left.E_{s 2}\right)$ Eşitlik (2) kullanılarak hesaplanmıştır. 


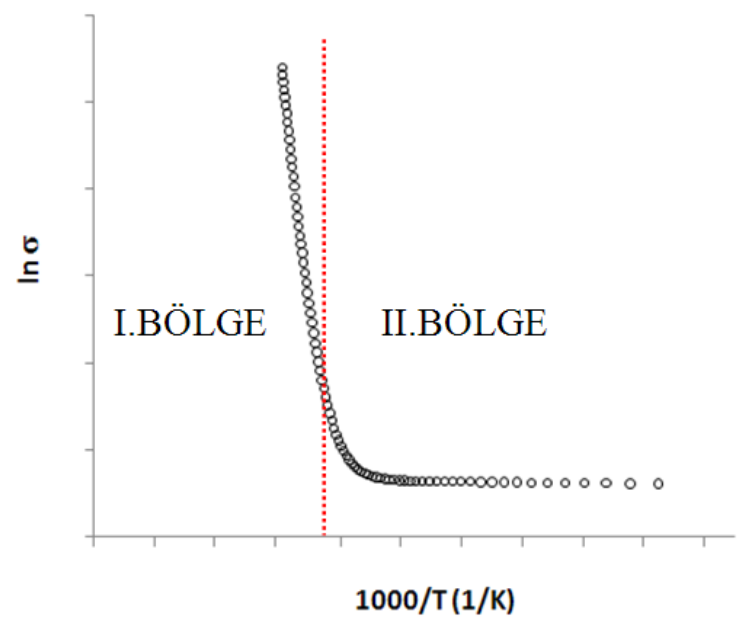

Şekil 3.1. Üretilen camlarda görülen tipik $\ln (\sigma)$ 1000/T grafiği.

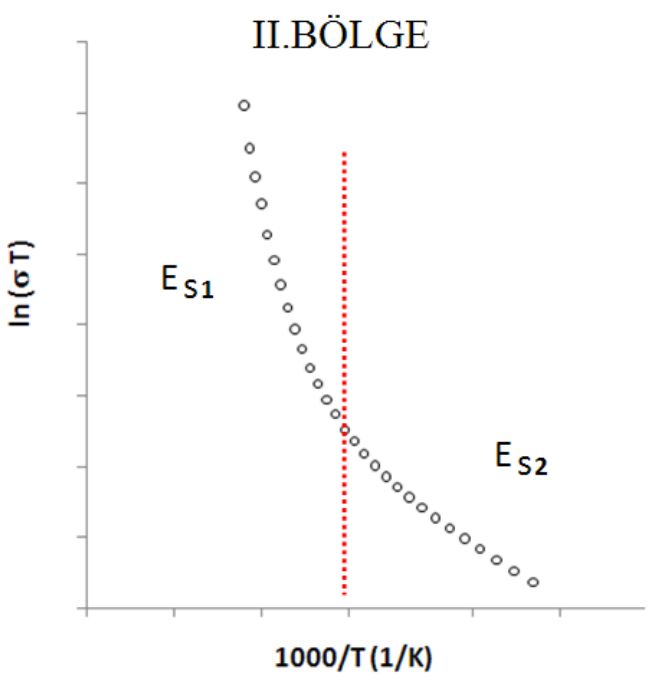

Şekil 3.2. SPH iletim mekanizmasının görüldüğü bölgenin şematik gösterimi.

Silikat tabanlı cam yapıların $65-420 \mathrm{~K}$ sıcaklık aralığında çizilen In $(\sigma) \sim 1000 / T$ grafikleri Şekil 3.3 'te ve $65-250 \mathrm{~K}$ sıcaklık aralığında çizilen In $(\sigma \mathrm{T}) \sim 1000 / \mathrm{T}$ grafikleri ise Şekil $3.4^{\prime} \mathrm{de}$ verilmektedir. Bu grafikler kullanılarak hesaplanan aktivasyon enerjileri ise Tablo $3.2^{\prime}$ de verilmiştir. Tablo 3.2 incelendiğinde 1. Bölgeler için hesaplanan aktivasyon enerjisi değerlerinin $\mathrm{ZnO}$ ilavesi ile arttığı görülmektedir. Bu durum, cam yapısına ilave edilen $\mathrm{ZnO}$ bileşiğinin bu konsantrasyonlarda cam yapıcı olarak görev aldığını işaret etmektedir. Bu durumda bağ yapmayan oksijen (non-bridging oxygen-NBO) yoğunluğu azalacak, yapı daha sıkı bir hal alacak, $\mathrm{Na}^{+}$iyonu için daha zor hareket edebileceği bir ağ yapısı oluşacak ve mobilitesi azalacaktır. Tablo 3.2' de verilen $E_{s 1}$ ve $E_{s 2}$ değerleri incelendiğinde, $\mathrm{ZnO}$ içeren silikat cam yapılarda bu değerlerde bir artış olduğu görülmektedir. Bu durumun yapıya giren $\mathrm{ZnO}^{\prime}$ nun cam yapıcı olarak davranması sonucu NBO yoğunluğunu azaltması ve bunun neticesinde lokalize durumlarının genişliğinin de azalmasından kaynaklandığını düşünmekteyiz. Böyle bir yapıda sıçrama iletimi için gerekli seviyelerin sayısı azalacak ve aktivasyon enerjilerinde bir artış gözlenecektir. 

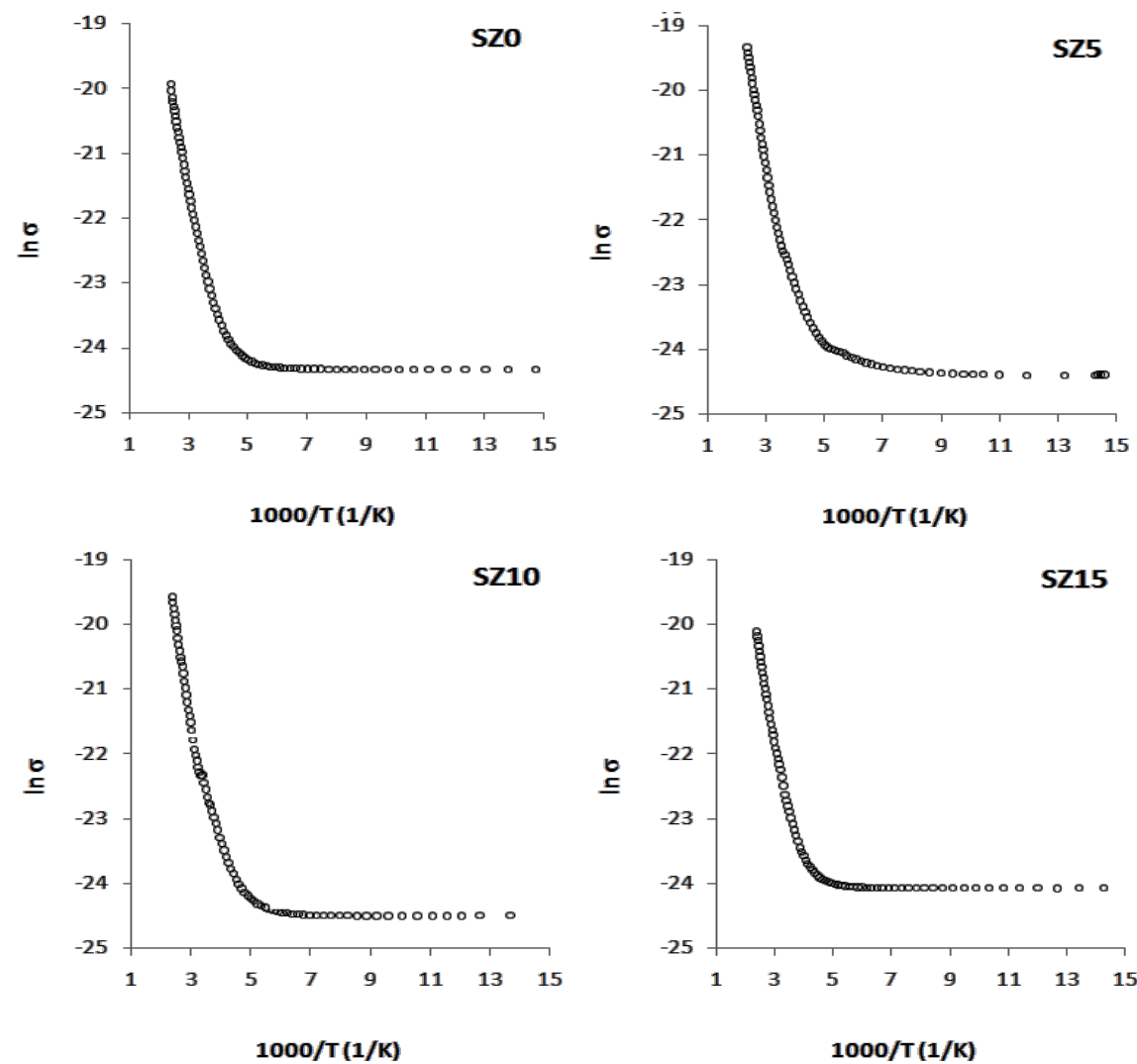

Şekil 3.3. Silikat camların 65-420 K sıcaklık aralığında çizilen In $(\sigma) \sim 1000 / T$ grafikleri
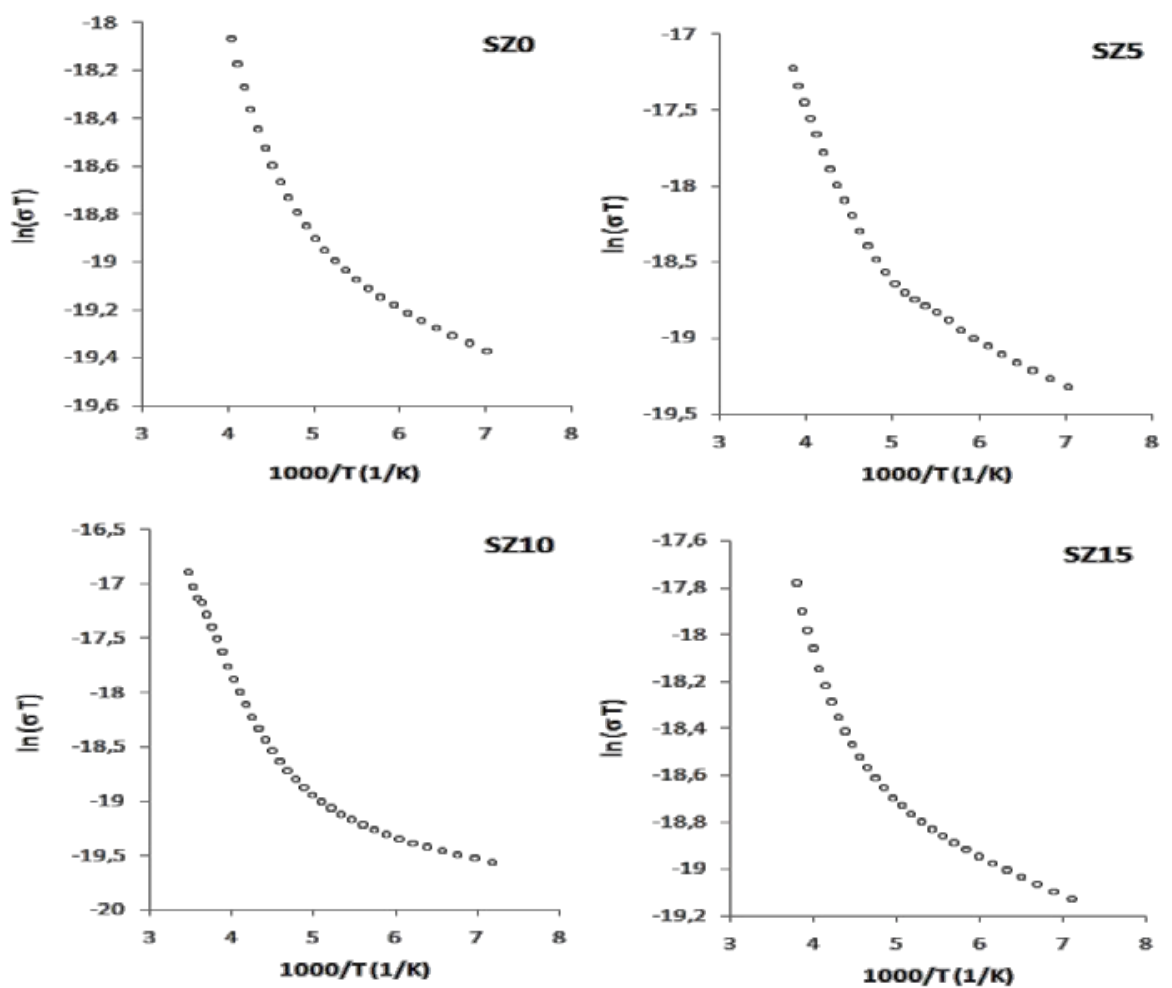

Şekil 3.4. Silikat camların 65-250 K sıcaklık aralığında çizilen In ( $\sigma \mathrm{T}) \sim 1000 / T$ grafikleri 
Tablo 3.2. Silikat cam yapıların aktivasyon enerji değerleri.

\begin{tabular}{llrr}
\hline NUMUNE & $\mathbf{E}_{\mathrm{a}}(\mathrm{meV})$ & $\mathbf{E}_{\mathrm{S1}}(\mathrm{meV})$ & $\mathbf{E}_{\mathrm{S2}}(\mathrm{meV})$ \\
\hline SZ0 & 196 & 87 & 14.8 \\
\hline SZ5 & 225 & 129 & 26.9 \\
\hline SZ10 & 265 & 138 & 16.6 \\
\hline SZ15 & 221 & 109 & 15.9 \\
\hline
\end{tabular}

\subsection{Optik Özellikler}

\subsection{1. Üretilen cam yapıların geçirgenlik ve soğurma spektrumları}

Şekil 3.5 ve $3.6^{\prime}$ da silikat tabanlı cam yapıların soğurma katsayısı ve geçirgenlik spektrumları

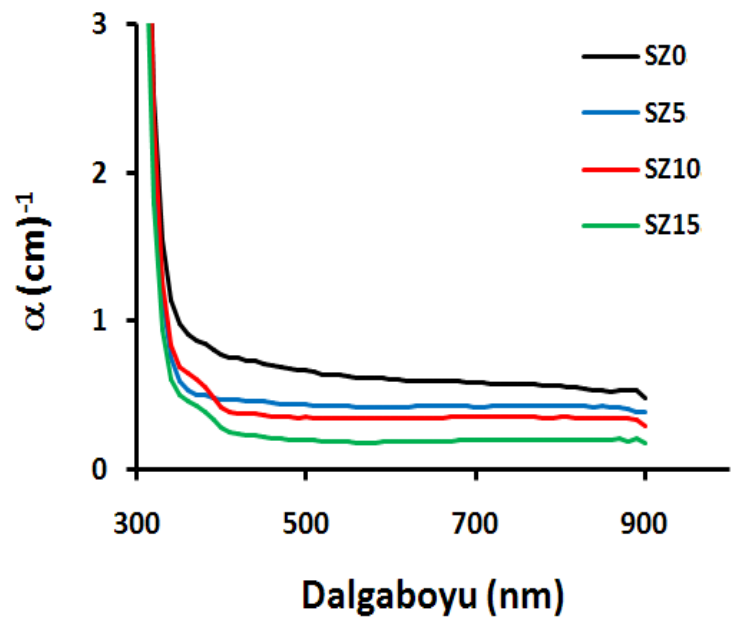

Şekil 3.5. Silikat camların soğurma katsayısı spektrumu.

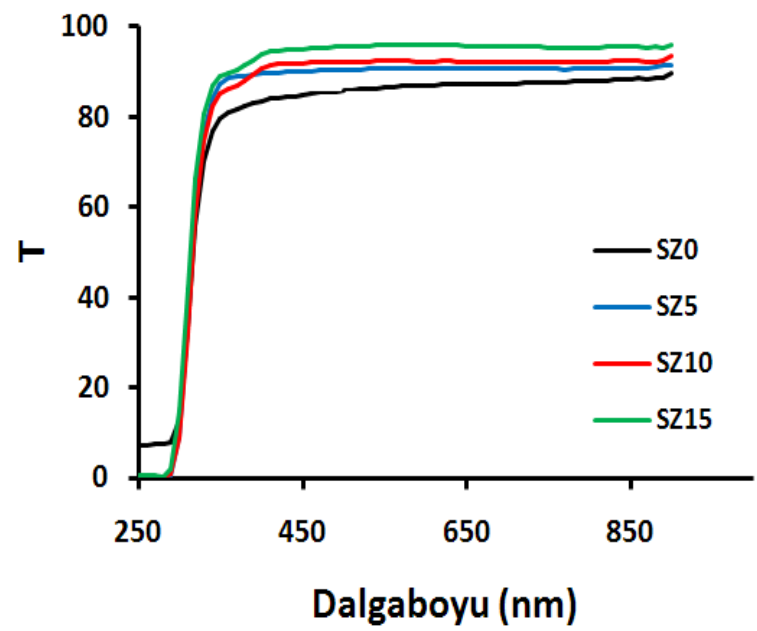

Şekil 3.6. Silikat camların geçirgenlik spektrumu. verilmiştir. İki grafik beraber incelendiğinde yapıya ZnO ilave edilmesiyle görünür bölgede geçirgenliğin arttığı ve soğurma katsayısının azaldığı görülmektedir. En yüksek geçirgenliğin gözlendiği SZ15 camında, geçirgenlik değeri 450 nm'de \%95 oranına kadar yükselmektedir.

\subsection{2. Üretilen cam yapıların optik bant yapılarının incelenmesi}

Camların optik bant aralıkları, UV absorpsiyon kenarından Tauc bağıntısı kullanılarak hesaplanabilir (Punia et al. 2011):

$\alpha h \vartheta=A\left(h \vartheta-E_{\text {opt }}\right)^{n}$

burada $\alpha$, absorpsiyon katsayısı; hu, gelen foton enerjisi; $A$, sabit; $E_{o p t}$, optik bant aralığı enerjisi; $n$ ise elektronik geçiş tipine bağlı bir parametredir. Direkt izinli geçişler için $n=1 / 2$; indirekt izinli geçişler için $n=2$ 'dir (Parmar et al. 2013).

Üretilen silikat camlarda daha iyi uyumun sağlandığı $\mathrm{n}=2$ durumu için çizilen $(\alpha h v)^{1 / 2} \sim \mathrm{hv}$ grafikleri Şekil 3.7'de ve hesaplanan optik bant aralığı değerleri ise Tablo 3.3 'de verilmiştir. ZnO ilavesiyle silikat cam yapıların optik bant aralığı değerlerinde bir artış gözlenmiştir. Bir cam ağ yapısında NBO yoğunluğunun absorpsiyon karakteristiklerinde önemli bir rol oynadığı bilinmektedir (Zaid et al. 2012). ZnO'nun silikat cam yapısına girerek ağ yapıcı olarak davranması sonucu NBO yoğunluğunu azalttığını ve bu durumun optik bant aralığı değerlerinde bir artışa sebep olduğunu düşünmekteyiz. 
Tablo 3.3. Silikat camların optik bant aralığı değerleri.

NUMUNE

$$
E_{\text {opt }}(\mathrm{eV})
$$

\begin{tabular}{cc}
\hline SZ0 & 3,654 \\
\hline SZ5 & 3,819 \\
\hline SZ10 & 3,822 \\
\hline SZ15 & 3,848 \\
\hline
\end{tabular}

\subsection{3. Üretilen cam yapıların optik sabitlerinin belirlenmesi}

Üretilen silikat camların optik sabitlerini belirlemek amacıyla Spektroskopik Elipsometre cihazı kullanılmıştır. Tüm numuneler için optik sabitler(kırılma indisi ve sönüm katsayısı) soğurmanın az olduğu bölgelerde sağlıklı sonuçlar veren Cauchy-Urbach modeli ile belirlenmiştir. Bu nedenle, camların soğurma spektrumları da göz önüne alınarak elipsometre ölçümleri 1200-1600 nm dalgaboyu aralığında alınmıştır. En uygun gelme açısı $75^{\circ}$ olarak belirlenmiş ve her bir cam örnek için $\Psi$ spektrumları alınmıştır. Ölçülen ve CauchyUrbach modeli ile belirlenen veriler için en iyi uyum (fitting) sağlanarak camların kırılma indisi ve sönüm katsayıları belirlenmiştir (Cetinkaya Colak et al. 2012). 

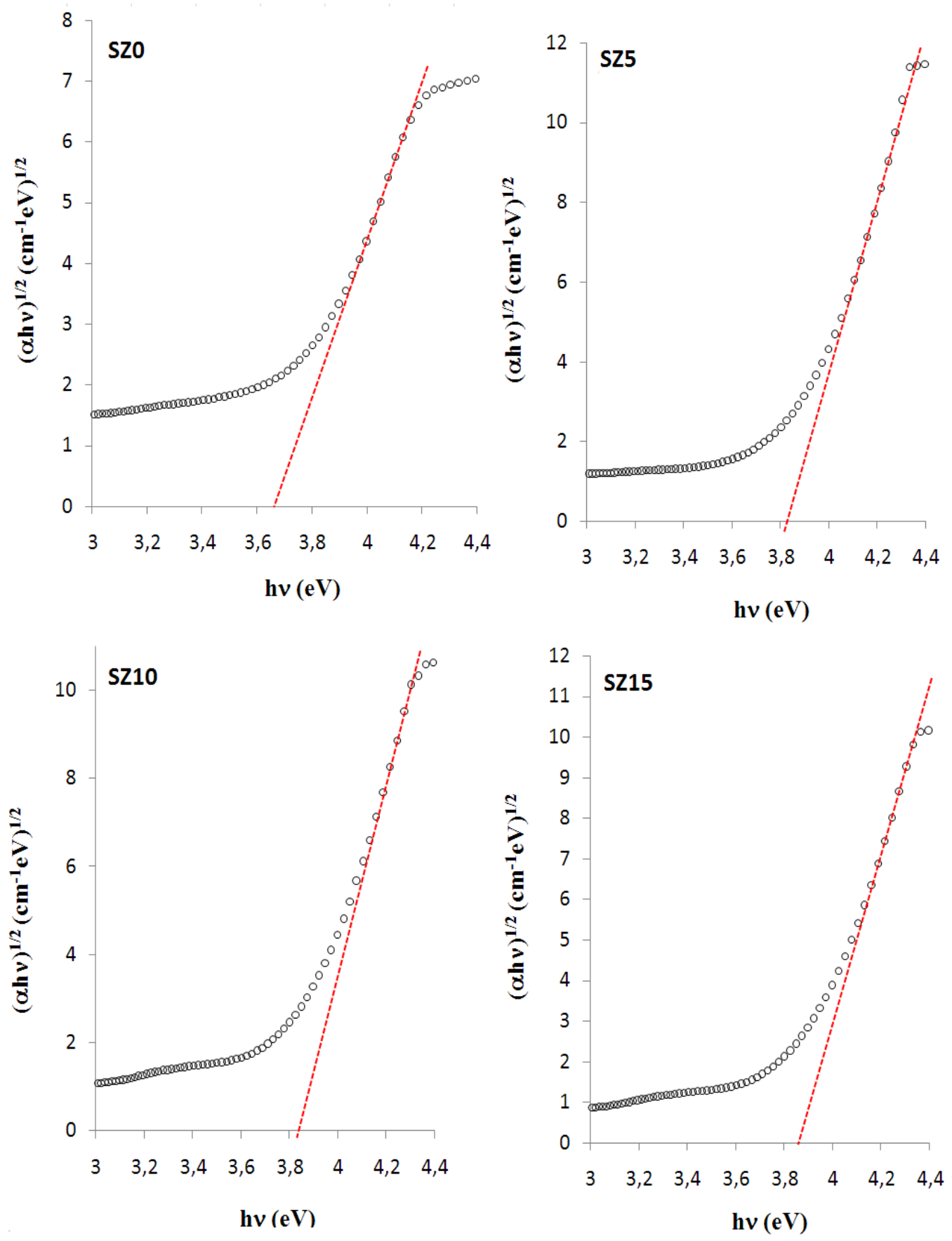

Şekil 3.7. Silikat camların $(\alpha h v)^{1 / 2} \sim$ hv grafikleri

Şekil 3.8'de Silikat tabanlı cam yapıların $\Psi$ spektrumları verilmektedir. Modelleme ile ilgili Cauchy-Urbach parametreleri Tablo 3.4'de verilmektedir. $\Psi$ spektrumları incelendiğinde tüm numuneler için deneysel veri ve teorik model arasındaki uyumun gayet iyi olduğu görülmektedir. 

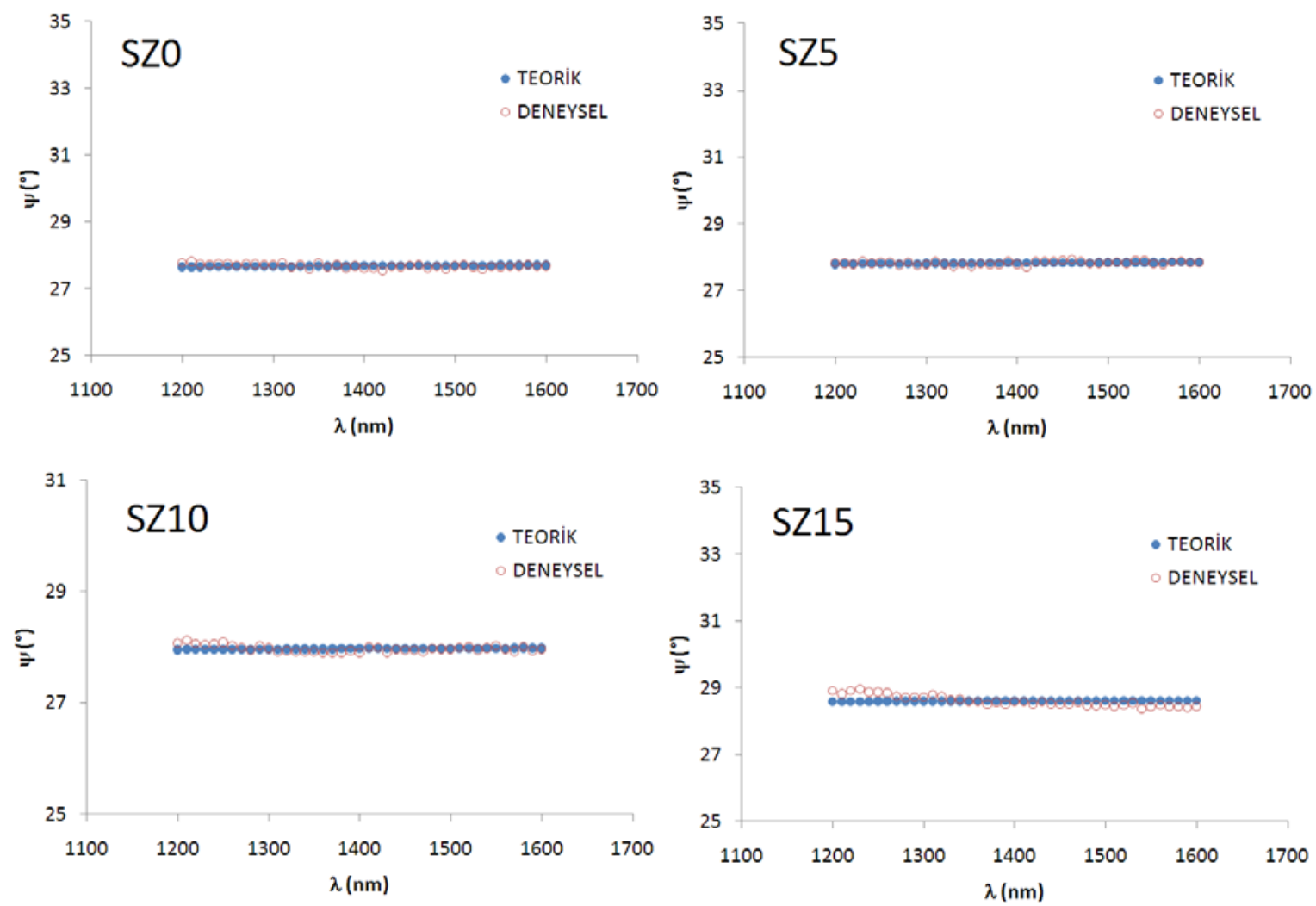

Şekil 3.8. Silikat tabanlı cam yapıları için $\Psi$ spektrumları.

Tablo 3.4. Silikat cam yapıların Cauchy-Urbach model parametreleri.

\begin{tabular}{cccccc}
\hline NUMUNE & $A_{n}$ & $\begin{array}{c}B_{n} \\
(n m)^{2}\end{array}$ & $\begin{array}{c}C_{n} \\
(n m)^{4}\end{array}$ & $A_{k}$ & $\begin{array}{c}B_{k} \\
(e V)^{-1}\end{array}$ \\
\hline BP0F & 1.697 & 0.002 & 0.003 & 0.068 & 1.11 \\
\hline BP5F & 1.715 & 0.009 & 0.118 & 0.112 & 1.13 \\
\hline BP10F & 1.737 & 0.008 & 0.008 & 0.102 & 1.13 \\
\hline BP15F & 1.786 & 0.007 & 0.005 & 0.147 & 1.18 \\
\hline
\end{tabular}

Silikat tabanlı cam yapıların kırılma indisi ve sönüm katsayısı spektrumları da Şekil 3.9 ve Şekil $3.10^{\prime}$ da verilmiştir. Kırılma indisi spektrumlarından görüldüğü gibi silikat yapısına giren ZnO miktarı arttıkça, kırılma indisi değerlerinde düzenli bir azalıs vardır. Bu durumun ağ yapıcı olarak davranan
ZnO'nun NBO yoğunluğunu azaltmasından kaynaklandığını düşünmekteyiz.

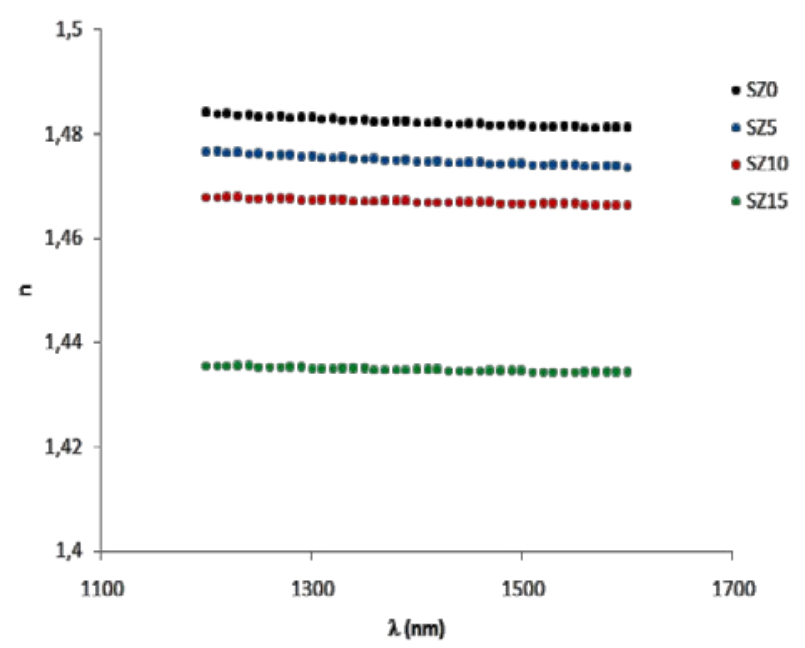

Şekil 3.9. Silikat cam yapıların kırılma indisi spektrumları. 


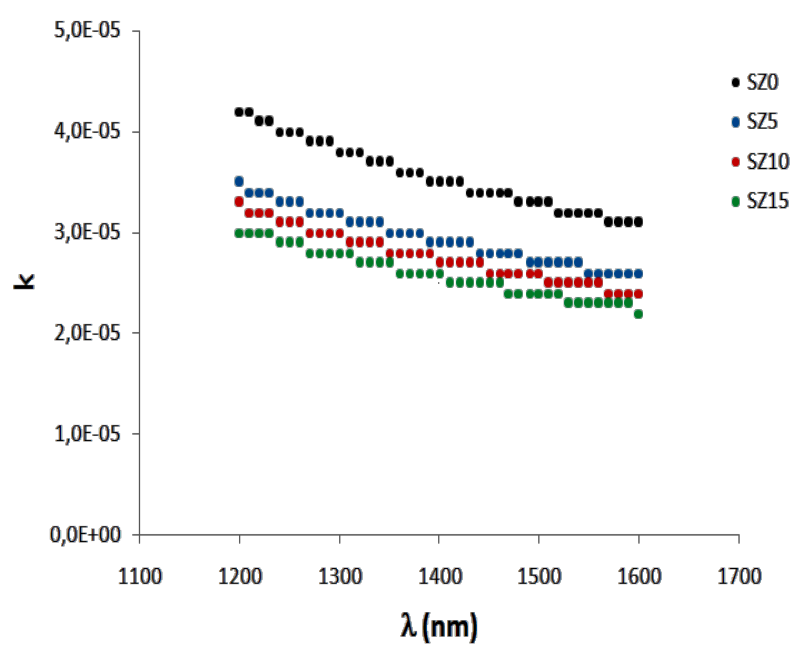

Şekil 3.10. Silikat cam yapıların sönüm katsayısı spektrumları.

\section{Tartışma ve Sonuç}

Bu çalışmada, çeşitli teknolojik alanlarda uygulama alanı bulan, farklı oranlarda ZnO içeren silikat cam yapılarının üretilmesi, elektriksel ve optik özellikleri üzerine geniş bir araştırmaya yer verilmiştir.

Üretilen cam yapıların elektriksel özellikleri incelenirken, yüksek sıcaklık bölgesinde, iyonik iletimin etkin olduğu bölgeler için klasik Arrhenius bağıntısı yardımıyla aktivasyon enerji değerleri hesaplanmıştır. Ayrıca, sıcaklığın düşük olduğu bölgelerde ise küçük polaron sıçrama (SPH) mekanizmasının etkin olduğu belirlenmiş ve buna bağlı aktivasyon enerjisi değerleri hesaplanmıştır. $\mathrm{Bu}$ hesaplamalar sonucunda, üretilen tüm silikat cam yapılarında, ZnO bileşiğinin ağ yapıcı olarak rol aldığı sonucuna varılmıştır. Tüm konsantrasyonlarda ZnO, yapıdaki NBO yoğunluğunu azaltmış ve aktivasyon enerjileri SZO numunesine göre daha yüksek çıkmıştır.

Yapılan optik ölçümler sonucunda, $\mathrm{ZnO}$ nun geçirgenlik değerlerinde artışa neden olduğu gözlenmiştir. Özellikle SZ15 numunesinde görünür bölgede yaklaşık \%95 geçirgenlik değerine ulaşılmıştır. Yapıda ağ yapıcı olarak davranan ZnO bileşiği NBO yoğunluğunu azaltmış ve bu durum daha yüksek optik bant aralığı değerlerinin ve daha düşük kırılma indisi değerlerinin görülmesine sebep olmuştur.

\section{Kaynaklar}

Abdel-Wahab, F., Aziz, M.S., Mostafa, A.G., Ahmed, E.M, 2006. Electrical conductivity and dielectric properties of some vanadium-strontium-iron unconventional oxide glasses. Materials Science and Engineering B, 134, 1-8.

Busio, M., Steigelmann, O., 2000. New frit glasses for displays, Glass Science Technology, 73, 319-325.

Cetinkaya Colak, S., Akyuz, I., Atay, F., 2016. On the dual role of $\mathrm{ZnO}$ in zinc-borate glasses. Journal of NonCrystalline Solids, 432, 406-412.

Chimalawong, P., Kirdsiri, K., Kaewkhao, J. and P. Limsuwan, P., 2012. Procedia Engineering, 32, 690-698.

Ding, L., Yang, Y., Jiang, X., Zhu, C. and Chen, G., 2008. Journal of Non-Crystalline Solids, 354, 1382-1385.

Kocabağ, D., 2002. Cam kimyası, özellikler, uygulaması, Birsen yayınevi, ìstanbul, 417 sf.

Morsi, R.M.M., Basha, M.A.F., Morsi, M.M., 2016. Synthesis and physical characterization of amorphous silicates in the system $\mathrm{SiO}_{2}-\mathrm{Na}_{2} \mathrm{O}-\mathrm{RO}(\mathrm{R}=\mathrm{Zn}, \mathrm{Pb}$ or $\mathrm{Cd})$. Journal of Non-Crystalline Solids, 439, 57-66

Parmar, R., Kundu, R.S., Punia, R., Kishore, N. and Aghamkar, P., 2013. Fe2O3 modified physical, structural and optical properties of bismuth silicate glasses. Journal of Materials, 2013, 5s.

Punia, R., Kundu, R.S., Hooda, J., Dhankhar, S., Dahiya, S. and Kishore, N., 2011. Effect of $\mathrm{Bi}_{2} \mathrm{O}_{3}$ on structural, optical and other physical properties of semiconducting zinc vanadate glasses. Journal of Applied Physics, 110, 33527.

Rosenthal, A.B. and Garofalini, S.H., 1987. Structural role of zinc oxide in silica and soda-silica glasses. Journal of American Ceramic Soc., 70, 821-826.

Zaid, M.H.M., Matori, K.A., Abdul Aziz, S., Zakaria, A. and Ghazali, M.S.M., 2012. Effect of ZnO on the Physical Properties and Optical Band Gap of Soda Lime Silicate Glass. International Journal of Molecular Sciences, 13, 7550-7558. 